Doi: $\underline{10.31578 / j e b s . v 5 i 1.183}$

\title{
Teacher Effectiveness of Some Selected Secondary Schools' Science, Technology, Engineering And Mathematics Subjects: Implication for Sustainable Development Using Science Education
}

\author{
Adewale Owodunni Saka* \\ Peter Aboyami Onanuga**
}

\begin{abstract}
This study examined the teacher effectiveness of the selected STEM subjects' teachers of physics, chemistry and biology at the senior secondary school level in ljebu North local area of Ogun state, Nigeria. All the fifty teachers delivering the selected STEM subjects were observed using and adapted Teachers' Effectiveness Observation Guide $(r=0.7)$. The data collected were analysed using descriptive and inferential statistics. The results revealed that teacher effectiveness of the selected STEM subjects' teachers was relevant. The results also indicated that teacher effectiveness of chemistry teachers was the best among the three categories of teachers. Furthermore, the findings revealed no significant gender difference in teacher effectiveness of the selected STEM subjects' teachers. The study discussed the implications of the findings for sustainable development using science education. It recommended among other things that periodic training should be organized for teachers in all areas of teaching dimensions, particularly in the use of activity-based instructional materials for science teaching.
\end{abstract}

Key words: Science teaching, STEM subjects, sustainable development, teacher effectiveness

\section{Introduction}

Science is the bedrock of any nation as no nation can achieve scientific and technological progress without paying adequate attention to its science education. Advancement in science and technology education will enable a nation to compete favourably with other nations in terms of developmental strides. Kaptan and Timurlenk (2013) posited that scientific knowledge is the collective human heritage capable of solving problems confronting mankind and that it also guarantees a purposeful life for the majority of individuals globally. Presumably, developed countries are where they are because they pay necessary attention to their science and technology education.

Akpan (2018) stated that the growth and development of any nation is pivoted on her STEM-type of science education. In a 2017 symposium held in Lagos on issues dealing with STEM education, Richard Kennedy, Director of Star Deep Water Petroleum argued that for Nigerian youths to survive in the $21^{\text {st }}$ century Information and Communication Technology (ICT)-driven society, it is necessary to develop their STEM capabilities beyond its present level (Nnaike, 2017). This is because STEM skills are highly indispensable, if Nigeria wants to develop scientifically and technologically to compete favourably in the emerging knowledgebased economies. Also at the programme, the Executive Director of Science Teacher Association of Nigeria (STAN), Professor Ben

\footnotetext{
* Department of Science and Technology Education, Olabisi Onabanjo University, Ago-Iwoye, Ogun state, Nigeria

** Department of Science and Technology Education, Olabisi Onabanjo University, Ago-Iwoye, Ogun state, Nigeria Corresponding Email: pierrenuga@gmail.com
} 
Akpan remarked that STEM has dual values to humans and their environment: it ensures that everybody has a basic literacy in science and prepares future engineers, medical doctors and other specialists in the society.

Similarly, Salau (2018) observed that STEM subjects can cultivate in students the skills of inquiry and discovery as well as fostering skills of persistence, teamwork, and transferability of the acquired knowledge in one domain to solve problems in other situations. STEM is a viable option to get Nigeria out of her numerous challenges (Lawal, 2017). Yusuf (2018) also maintained that the lack of severe shortages of skilled manpower in the country can be remedied by using STEM education. Meanwhile, Medium Corporation (2018) reported that more than fifty percent of jobs that will be available worldwide by 2030 will be STEM-related. It, therefore, means that STEM education, if given adequate attention, can give Nigeria competitive advantages over other nations. From the foregoing, it suggests that science education in the form of STEM has abundant benefits to mankind.

Relatedly, Akpan (2017) argued that science education is in line with sustainable development. Sustainable development is described as a process whereby people achieve their target and full potential over a period of time while preserving the elasticity of economic, social and environmental systems (Obianuju, Obiajulu \& Ella, 2013). Ogunmade cited in Obianuju et al. (2013) also posited that sustainable development requires a nation to recognise her science education and pay due attention to it. This buttressed the idea of Akpan (2017) that science education can be used to achieve sustainable development. Similarly, Tickly et al. (2018) stated that STEM knowledge is important to address challenges emanating from climate changes which are core to sustainable development. In related development, Ohunene and Ebele (2014) also argued that, if science education is strengthened, it will provide the right support to Nigeria towards sustainable development. These submissions also lend credence to the capabilities of STEM education in solving myriads of problems confronting Nigeria in various facets of her development.

According to Tickly et al. (2018), it is assumed that the general education provided at the secondary school level will lay the foundation for STEM education at the tertiary level. However, studies have revealed that all is not well with the teaching and learning of science education in the Nigeria education system. Ugo and Akpoghol (2016) reported that, in spite of the high number of secondary education leavers seeking admissions to higher education in Benue State, only few of them applied for STEM-related courses. This suggests that there is a problem with the teaching and learning of the STEM-related subjects at that level in the state. The researchers recommended that stakeholders should come together to solve problems related to facilities, interests and teaching methods. Obianuju et al. (2013) also observed that, despite the importance of science education for national development, Nigeria has lacked sustainable science education since gaining its independence. Consequently, the country has remained less-industrialized and below the poverty level. Importantly, Medium Corporation (2018) lamented that STEM education is the most adversely affected aspect of education in Nigeria and as a result, Nigerian youths lacked basic skills to compete for STEM-skills-related jobs.

However, several interventions put in place by different stakeholders such as RoboRAVE International Education Academy, Integrated Digital Payment and Commerce Company (Interswitch), Huawei Technologies, Chevron Business in Nigeria, and Science Teachers Association of Nigeria (STAN) to improve the teaching and learning of STEM-related subjects are gaining a certain impact (Onanuga \& Saka, 2018), but the problems are still noticeable in the inability of the country to compete favourably with other scientifically and technologically advanced nations. In the meantime, research findings have linked teachers to the attainment of the goals of science education and STEM education for sustainable development (Mileska et al., 2017; Oviawe; 2016; Ugo \& Akpoghol, 2016). This may be due to the pivotal roles of teachers in the teaching and learning of science education. The quality of teaching and of learning resources, the qualification of teachers are some of the factors inhibiting the development of science education in Nigeria (Omorogbe \& Ewansiha, 2013). This means that teachers determine the quality of science education of a nation. In fact, teachers are core to the development of any educational system, since there is no education system that can 
rise above the quality of its teachers. Darling-Hammond (2010) maintained that teachers determine the success or failure of any educational programme, and every aspect of school reforms depends for success on highly-skilled teachers. This implies that teacher effectiveness can make the success of any educational initiatives, including STEM education for sustainable development.

Clinton et al. (2016) observed that teacher qualification and teacher effectiveness are being used interchangeably, despite their difference. Whereas teacher effectiveness can be perceived as a continuum covering the extent to which a teacher is able to progress students' outcomes using students achievement results and other summative tools, teacher qualification is the measure of teacher's attributes such as capabilities, training, knowledge or belief. Improvement in teacher effectiveness and quality is capable of radically increase in the students' outcomes at school and system levels. Darling-Hammond (2000) argued that the effects of quality teaching on student outcomes are greater than those that arise from students' backgrounds. The impact can be positive or negative, with the effect of poor quality teaching being cumulatively adverse on students' results. Little, Goe and Bell (2009) observed that two of the most widely used measures of teacher effectiveness are the value-added model and classroom observations. Other methods are principal evaluations, analyses of classroom artefacts, portfolios, self-reports of practice and student evaluation. But this study employed classroom observation measure.

Mixed findings on teacher effectiveness and the teaching dimensions that contribute to it have been reported in literature. Mileska et al. (2017) examined the instructional practice of secondary school biology teachers. The study which employed the value-added method of investigation reported that secondary school biology teachers who had a well-managed classroom environment and who provided opportunities for students to engage in student-directed experiences were more likely to increase students' outcomes. This implies that this kind of teachers will be more effective in improving students' learning outcomes. Saikia (2016) also found that the majority of the secondary school science teachers of Bokakhat sub-division are highly effective. However, the study indicated no significant teacher effectiveness difference among chemistry, physics and biology teachers. The teachers do not differ in terms of classroom management, use of instructional materials, etc. Similarly, the study of Johnson, Zhang and Kahle (2012) revealed that students who had more effective teachers performed increasingly better over time compared to those taught by less effective teachers over the same period of time.

Dash and Barman (2016) reported that the overall teaching effectiveness of secondary school teachers in the District of Purba Medinapur, West Bengal was high. Islahi and Nasreen (2013) revealed that teachers need to have basic teaching skills as part of their repertoire of effectiveness and suggested that modules for teaching skills should be developed. In Nigeria, the report of Oviawe (2016) indicated that the effectiveness of basic technology teachers was low. The findings also linked students' achievement to teacher effectiveness. Corroboratively, Onyekuru and Ibegbunam (2013) reported that the teacher effectiveness of the secondary school teacher in Emohua Local Government Area of Rivers State is below average. The authors attributed this to teaching experience and teachers' qualification. Kiadese (2011) recorded relatively low teacher effectiveness among vocational subject teachers in Ogun State, Nigeria. Meanwhile, Badau (2012) concluded that teachers need to improve their effectiveness in various aspects of teacher effectiveness.

Research findings have revealed that gender influences the effectiveness of secondary school teachers, but they the impact is contradictory. Islahi and Nasreen (2013) noted that teaching requires various complex skills, insight, intelligence, knowledge, management and competence, dynamism and diligence which may interplay with teachers' gender. The authors reported that gender difference accounts for individual differences in teachers' practice. Importantly, the study concluded that, since the quality of education is determined by teachers' degree of effectiveness, there is a need for substantive and methodological focus on gender-specific responsibilities and requirement in order to make both female and male teachers to be maximally productive. 
Ahiatrogah (2017) indicated that gender has an effect on acquisition of teaching skills and recommended that all policymakers in the area of teaching practice should pay a due attention to gender-related issues in the development of teaching skills. Similarly, Degi and Zangmu (2017) reported a significant difference in the effectiveness of male and female teachers in secondary schools of Tawang district of Arunachal Pradesh. This finding corroborated that of Saini and Joshi (2015) that there exists gender difference among secondary school teacher according to their effectiveness. The results also revealed that female teachers were more effective than male teachers. Furthermore, the studies of Bhat (2017), as well as Sagar and Parveen (2017) indicated that there is significant gender difference between the teacher effectiveness in secondary school.

Conversely, Oviawe (2016) as well as Onyekuru and Ibegbunam (2013) reported no significant difference among the secondary school teachers' effectiveness on the basis of their gender. Biswas (2017) also found no significant gender difference in the secondary school teacher effectiveness. Relatedly, Shah and Udgaonkar (2018) reported that gender is not a barrier to teacher effectiveness. However, female teachers are preferable to male teachers for female students due to the possibility of more comfortable interaction. Females are compassionate, hardworking, sincere, and have audible and pleasant voices.

From the foregoing, it is obvious that teachers' effectiveness is critical to achieving the goals of STEM education, especially in solving myriads of problems facing the country. Hence, this study examined the effectiveness of teachers teaching physics, chemistry and biology at the senior secondary school level of education. Teacher effectiveness in this study represents teaching dimensions such as classroom teaching approach, instructional material usage, students' activities, classroom management, teachers' personalities and evaluation of student works by teachers. Also, conflicting findings have been reported on gender gap in teacher effectiveness and this motivated the researchers to try to find out whether significant gender difference actually existed in teacher effectiveness with a view to contributing to knowledge in the aspect of literature.

To this end, the authors of this paper were guided by the following research questions and hypotheses:

\section{Research Questions}

i. What is the teacher effectiveness of the selected STEM subjects of physics, chemistry and biology teachers in senior secondary schools in ljebu-North local government area, Ogun state?

ii. What is the implication of the findings on teacher effectiveness to the attainment of sustainable development in Nigeria, using science education?

\section{Hypotheses}

i. There is no significant difference in the teacher effectiveness of the selected STEM subjects' teachers across subjects being taught (physics, chemistry or biology) in ljebu-North local government area, Ogun state.

ii. There is no significant difference in the selected STEM subjects' teacher effectiveness mean scores based on gender in ljebu-North local government area, Ogun state.

\section{Methodology}

A survey research design of observation type was employed to achieve the objectives set for the study. The study examined the effectiveness of senior secondary school teachers delivering the selected STEM subjects of physics, chemistry and biology through an observation schedule guide. The observational study required from the researchers and their trained research assistants to visit all sixteen (16) public secondary schools in ljebu-North local government area of Ogun state, Nigeria. The local 
government area was chosen due to its proximity to the place of work of the researchers so as to minimize the resources and stress associated with the study of this nature. All fifty teachers delivering the selected STEM subjects of physics, chemistry and biology were involved in the study. This comprised of sixteen (16) physics teachers, fourteen (14) chemistry teachers and twenty (20) biology teachers.

The instrument used for this study was a 20-item Teacher's Effectiveness Observation Guide (TEOG) adapted from Olabisi Onabanjo University, Ago-Iwoye, Faculty of Education Student's Observation Record. The instrument is a four-point Likert scale ranging from very good to good, fair and poor $(4,3,2$, and 1 points, respectively). It covers teacher effectiveness dimensions such as classroom teaching, instructional material, students' activities, classroom management, teachers' personality and evaluation. The instrument has two sections. Section A elicited teachers' demographic information while section B was a rating scale based on the raters' observations of the teachers in the classroom during the educational process.

The instrument was validated by subjecting it to the critiques of two lecturers in the Department of Educational Foundation and Counselling and the Department of Science and Technology Education of the University. The experts' comments were used to modify the instrument to arrive at the final one. The reliability of the instrument was obtained by using it to observe the same set of ten teachers in a local government different from where the one in the study. The participants were selected by two observers. Thereafter the ratings of the two observers were subjected to inter-rater reliability using Cronbach alpha reliability statistic which yielded Alpha coefficient of 0.70 , which is sufficiently high.

The researchers sought the approval of the authorities of the schools visited and solicited the support of the affected teachers with the assurance that the data gathered would be used for research purposes only. The observational activities lasted for two months due to the number of teachers to be observed and in order to conduct a diligent observation devoid of biases.

\section{Data Analysis}

The observation data from TEOG were classified into four levels adapting the J. W Best's criteria described in Dash and Barman (2016) as shown below:

Highest score - Lowest Score

Number of levels

$=$

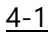

4

$=\quad 0.75$

Table 1: Criteria for determining level of teaching effectiveness of the selected teachers

\begin{tabular}{lll}
\hline S/No. & Range of Scores & Level of Teaching Effectiveness \\
\hline 1. & $1.00-1.70$ & Low \\
2. & $1.71-2.50$ & Moderate \\
\hline
\end{tabular}




\begin{tabular}{lll}
\hline 3. & High \\
$4.51-3.20$ & Very high \\
\hline
\end{tabular}

\section{Results of Data Analyses}

Table 2: Descriptive statistics of teachers' gender composition across subjects

\begin{tabular}{lccc}
\hline Subjects & \multicolumn{2}{c}{ Gender } & Total /subject \\
\hline & Male (\%) & Female (\%) & \\
Physics & $6(12)$ & $10(20)$ & 16 \\
Chemistry & $3(6)$ & $11(22)$ & 14 \\
Biology & $5(10)$ & $15(30)$ & 20 \\
Total & $\mathbf{1 4 ( 2 8 )}$ & $\mathbf{3 6}(\mathbf{7 2})$ & $\mathbf{5 0}$ \\
\hline
\end{tabular}

Table 2 revealed that only $28 \%$ of the teachers were male, while the female teachers constituted $72 \%$ of the study participants

Research Question: What is the teacher effectiveness of the selected STEM subjects of physics, chemistry and biology teachers in senior secondary schools in ljebu-North local government area, Ogun state?

Table 3: Summary of overall teacher effectiveness of the selected STEM subjects of Physics, chemistry and biology teachers

\begin{tabular}{|c|c|c|c|c|c|c|}
\hline $\begin{array}{l}\text { S } \\
\text { /No. }\end{array}$ & Name of Dimensions & $\begin{array}{l}\text { Number } \\
\text { of items }\end{array}$ & $\begin{array}{l}\text { Number } \\
\text { of teachers }\end{array}$ & Mean & Std. Deviation & Remark \\
\hline 1. & Classroom Teaching & 5 & 50 & 3.124 & 2.212 & high \\
\hline 2. & Instructional Material & 4 & 50 & 2.665 & 3.286 & high \\
\hline 3. & Students' Activities & 2 & 50 & 3.180 & 1.495 & high \\
\hline 4. & Classroom Management & 3 & 50 & 3.200 & 1.927 & high \\
\hline 5. & Teachers' Personality & 3 & 50 & 3.490 & 1.631 & very high \\
\hline 6. & Evaluation & 3 & 50 & 3.033 & 2.112 & high \\
\hline
\end{tabular}


Table 3 indicated that, in general, the teacher effectiveness of the teachers handling the selected STEM subjects of physics, chemistry and biology in ljebu-North local government area, Ogun state is high. The table also indicated that such teaching dimensions as teachers' personality recorded the highest mean score (3.490), while the instructional material recorded the lowest mean score (2.665).

Hypothesis 1: There is no significant difference in the teacher effectiveness of the selected STEM subjects' teachers across subjects being taught (physics, chemistry or biology) in ljebu-North local government area, Ogun state.

Table 4: Descriptive statistics of teacher effectiveness mean scores across selected subjects

\section{Subjects Mean Std. deviation Std. Error Minimum Maximum}

\begin{tabular}{lccccc} 
Physics & 59.19 & 7.910 & 1.977 & 43 & 72 \\
Chemistry & 64.43 & 5.360 & 1.626 & 53 & 75 \\
Biology & 62.35 & 7.271 & 1.432 & 43 & 74 \\
Total & $\mathbf{6 1 . 9 2 1}$ & $\mathbf{7 . 1 8 2}$ & 1.016 & $\mathbf{4 3}$ & $\mathbf{7 5}$ \\
\hline
\end{tabular}

Table 4 revealed that chemistry teachers recorded the highest mean score of 64.43 followed by biology and physics with 62.35 and 59.19 respectively. This implies that chemistry teachers are the most effective among the three groups of teachers. Besides, chemistry teachers also recorded the best minimum and maximum teacher effectiveness score of 53 and 75 respectively when compared to minimum and maximum scores of other groups.

Table 5: Teachers' effectiveness scores by subjects: analysis of variance

\begin{tabular}{llllll}
\hline Sources of variance & Sum of squares & df & Mean square & $F$ & Sig. \\
\hline Between groups & 211.264 & 2 & 105.632 & 2.143 & 0.129 \\
Within groups & 2316.416 & 47 & 49.285 & & \\
Total & 2527.680 & 49 & & \\
\end{tabular}


Table 5 indicated that no significant difference in the teacher effectiveness mean score across the selected STEM subjects of physics, chemistry and biology, $F(2,49)=0.129, p>0.05)$. This implies that the teacher effectiveness mean scores did not differ significantly across teachers of chemistry, physics and biology. Thus, the null hypothesis which states that there is no significant difference in the teacher effectiveness of the selected STEM subjects' teachers across subjects being taught (physics, chemistry or biology) in ljebu-North local government area, Ogun state is provisionally retained. However, as mentioned earlier, descriptive statistics in table 4 revealed that chemistry teachers recorded the highest mean score of 64.43 as against the 62.35 and 59.19 recorded by biology and physics respectively. This implies that teacher effectiveness of chemistry teachers is the best in the given sample among the three categories of teachers. However, the difference is not significant as reflected by effect size, $r=0.28$ which represents an unassertive effect.

Hypothesis 2: There is no significant difference in the selected STEM subjects' teacher effectiveness based on gender in ljebuNorth local government area, Ogun state.

Table 3: Summary of independent t-test analysis on the teacher effectiveness of the selected STEM subjects by gender

\begin{tabular}{lllllllll}
\hline Gender & Number & Mean & Std. deviation & Mean difference & Std. error mean & Df & T & Sig. (2 tailed) \\
\hline Female & 36 & 62.50 & 7.016 & 0.637 & 0.169 & 48 & 0.914 & 0.365 \\
Male & 14 & 60.43 & 7.653 & & 2.045 & & & \\
\hline
\end{tabular}

Table 3 indicated that, on average, the female teacher effectiveness (Mean $=62.50$, Std. Error $=0.169$ ) is better than that of their male counterparts (Mean $=60.43$, Std. Error $=2.045$ ). However, this difference is statistically not significant $t(48)=0.914$, $p>0.05$. The effect size of the difference is also weak $(r=0.13)$. Meanwhile, from output of this table, the hypothesis which states that there is no significant difference in the selected STEM subjects' teacher effectiveness mean scores based on gender in ljebuNorth local government area, Ogun state is provisionally retained. This implies that there is no significant gender difference in the teacher effectiveness of the selected STEM subjects' teachers.

\section{Discussion}

The findings revealed that teacher effectiveness of the selected STEM subjects' teachers of physics, chemistry and biology was good. This may be due to the teaching approach adopted, teachers' personalities, evaluation methods employed during teaching, varieties of students' activities given as well as the attention paid to classroom management. The finding may further be attributed to the impact of different interventions put in place by stakeholders to enhance the teaching and learning of STEM education. In addition, the finding may be linked to the higher number of female teachers in the study. According to Saini and Joshi (2015), also female teachers are more effective than male teachers. Therefore, it is expected that since the number of female teachers who participated in the study is higher that of male teachers, the overall teacher effectiveness may be affected positively. Although, teacher effectiveness in the use of instructional material was high, but it is not as effective as other dimensions of teacher effectiveness observed during the study. This was due to either lack of instructional materials for the teaching and learning or the non-usage of the available ones. Meanwhile, the finding concerning high teacher effectiveness is in line with that of Dash and Barman (2016) who reported that the overall teaching effectiveness of secondary school teachers in the District of Purba Medinapur, West Bengal was high. The finding, however, contradicts some findings on teacher effectiveness in Nigerian 
educational context. For instance, while Oviawe (2016) reported that the effectiveness of basic technology teachers was low. The study by Onyekuru and lbegbunam (2013) also revealed that the teacher effectiveness of the secondary school teachers in Emohua local government area of Rivers state is below average. On the part of the study of Kiadese (2011), low teacher effectiveness among vocational subject teachers in Ogun state, Nigeria was reported. This may be related to particular schools and other educational institutions or regions.

Similarly, the finding revealed no significant difference in the teacher effectiveness across the selected STEM subjects' teachers of physics, chemistry and biology. This may also be due to the impact of several interventions put in place to promote the teaching and learning of STEM education. It may be attributable to the teacher effectiveness of the selected subjects' teachers in all the teaching dimensions observed in the study. Above all, it may also be linked to the number of female teachers who participated in the study from each of the groups. This finding corroborates that of Saikia (2016) that found no significant teacher effectiveness difference among chemistry, physics and biology teachers of Bokakhat sub-division. However, chemistry teacher effectiveness was the best among the three subjects' teacher effectiveness. It was better than that of biology and physics teachers.

Furthermore, the study revealed that there is no significant gender difference in the teacher effectiveness across the selected STEM subject teachers of physics, chemistry and biology. Meanwhile, on average, the female teacher effectiveness is higher than that of their male counterparts. This may be due to the fact that female teachers are perceived as kind-hearted, painstaking, truthful, and have audible and pleasant voices (Shah \& Udgaonkar, 2018). This finding lends credence to the statement of Shah and Udgaonkar (2018) that gender is not a barrier to teacher effectiveness. It also reinforces the earlier findings of Oviawe (2016), as well as of Onyekuru and Ibegbunam (2013) that no significant difference exists among secondary school teachers' effectiveness on the basis of their gender.

\section{Implications for sustainable development}

The implication of the findings to sustainable development in Nigeria is that the attainment of the sustainable development using science education may be positively affected. This implies that Nigeria may not be able to meet the agenda 2030 for sustainable development which the country is a signatory unless teaching STEM subjects is improved. This is because teachers who are the core of the actualization of the dream of a better life using science education as one of the instruments have their teacher effectiveness mean score within the range of 'high' instead of 'very high'.

Most surprising is that the use of instructional materials to facilitate learning recorded the lowest mean score. This is probably due to teachers' poor usage or non-usage of instructional materials.

\section{Conclusion}

The study examined the teacher effectiveness of selected STEM subjects in ljebu-North local government area of Ogun state. The study concluded that teacher effectiveness of the selected STEM subjects was high. At the same time, no statistically significant difference was found among the teacher effectiveness of the selected STEM subjects' teachers, although the chemistry teacher effectiveness was the highest. Furthermore, the study concluded that there is no significant gender difference in teacher effectiveness of the selected teachers. 


\section{Recommendations}

Based on the findings, it is recommended that all stakeholders in STEM education should continue to help teachers to develop their effectiveness in all the areas of teaching dimensions. This is necessary because the target teacher effectiveness should be 'very high' and not just 'high' as revealed in the study. In this connection, periodic training should be organized for teachers, particularly in the area of activity-based instructional materials application in science teaching and learning. In addition, psychology-induced trainings should be organised for male science teachers to improve their effectiveness, so that they can also learn to be kind-hearted, painstaking, truthful, and develop audible and pleasant voices during teaching learning process like their female counterparts.

\section{References}

Ahiatrogah, P.D. (2017). Gender dimension in the development of effective teaching skills among University of Cape Coast (UCC) distance education students. World Journal of Education, 7(4), $12-23$.

Akpan, B. (2017). Science education for sustainable development. In Taber K.S., Akpan B. (eds.). Science Education. New Directions in Mathematics and Science Education. Rotterdam: Sense Publishers.

Akpan, B. (2018). Science, Technology, Engineering and Mathematics (STEM) and Economic Growth. Abuja: The STAN Place.

Badau, K.M. (2012). Assessing increased teacher effectiveness in secondary school classrooms in Adamawa State of Nigeria. Multidisciplinary Journal of Empirical Research, 10(1), 1-9.

Bhat, R.L. (2017). A study of teaching effectiveness of prospective teachers in relation to stream and gender. Retrieved September 1 , 2019

from https://www.amity.edu/aien/aijte/articles2017/A\%20STUDY\%20OF\%20TEACHING\%20EFFECTIVENESS\%20OF\%20PROSPEC TIVE\%20TEACHERS\%20IN\%20RELATION\%20TO\%20STREAM\%20AND\%20GENDER.pdf

Biswas, M. (2017). A study of teacher effectiveness of secondary school teachers in relation to gender, locations and academic stream. International Educational and research Journal, 3(9), 47-48.

Clinton, J.M., Anderson, M., Dawson, G., Dawson, A., Bolton, S., \& Mason, R. (2016). Systems, Frameworks and Measures of Teacher Effectiveness. Melbourne, Australia: Centre for Programme Evaluation.

Darling-Hammond, L. (2000). Teacher quality and students' achievement: A review of state policy evidence. Education Policy Analysis Archives, 8(1), 1-44.

Darling-Hammond, L. (2010). Evaluating teacher effectiveness. Retrieved September 1, 2019 from https://files.eric.ed.gov/fulltext/ED535859.pdf

Dash, U. \& Barman, P. (2016). Teaching effectiveness of secondary school teachers in Purba Medinipur, West Bengal. IOSR Journal of Humanities and Social Sciences, 21(7), 50-56.

Degi, K., \& Zangmu, L. (2017). A study on teaching effectiveness of secondary school teachers of Tawang District, Arunachal, Pradesh. International Education and Research Journal, 3(9), 13-14. 
Islahi, F. \& Nasreen, A. (2013). Who make effective teachers, men or women? An Indian perspective. Universal Journal of Educational Research, 1(4), 285-293.

Johnson, C.C., Zhang, D., \& Kahle, J.B. (2012). Effective science instruction: Impact of high-stakes assessment performance. Association for Middle Level Education, 53 (9), 1-14.

Kaptan, K. \& Timurlenk, O. (2012). Challenges for science education. Procedia - Social and Behavioural Sciences, 51(2012), 763771.

Kiadese, A.L. (2011). An assessment of the teaching effectiveness of prevocational subjects in Ogun State, Nigeria. International Journal of Vocational and Technical Education, 3 (1), 5-8.

Lawal, I. (2017). STEM education as a catalyst for national development. Retrieved September 1, 2019 from https://t.guardian.ng/features/focus/stem-education-as-a-catalyst-for-national-development/

Little, O., Goe, L., \& Bell, C. (2009). A practical guide to evaluating teacher effectiveness. Retrieved September 1, 2019 from https://files.eric.ed.gov/fulltext/ED543776.pdf

Medium Corporation. (2018). Declining interest in STEM education in Nigeria: The need for urgent intervention. Retrieved September 1, 2019 from https://medium.com/@BHMblog/declining-interest-in-stem-in-nigeria-the-need-for-urgentintervention-749dcd239fa5

Mileska, J.N., Shattuck, T., Holtzman, S., McCaffrey, D.F., Duchesneau, N.Q., \& Sticklier, L. (2017). Understanding science teaching effectiveness: Examining how science-specific and generic instructional practice relate to student achievement in secondary school science classrooms. International Journal of Science Education, 39(18), 2594-2623.

Nnaike (2017). Revisiting STEM education as vital for national growth. Retrieved September 1, 2019 from http://www.thisdaylive.com/index.php/2017/10/18/revisiting/-stem-education-as-vital-for-national-growth/?amp

Obianuju, O.S., Obiajulu, A.N., \& Ella, F.A. (2013). Science education for sustainable development in Nigeria: Challenges and principles. Academic Journal of Interdisciplinary Studies, 2(6), 159-165.

Ohunene, O.C. \& Ebele, O.B. 92014). Science education and sustainable development in Nigeria. American Journal of Educational Research, 2(8), 595-599.

Omorogbe, E. \& Ewansiha, J.C. (2013). The challenge of effective science teaching in Nigerian secondary schools. Academic Journal of Interdisciplinary Studies, 2(7), 181-188.

Onanuga, P.A. \& Saka, A.O. (2018). Trend analysis of students' academic performance in selected Science, Technology, Engineering, and Mathematics subjects in Ogun State Basic Education Certificate Examination (OG-BECE), Nigeria, from 2011 to 2015: A projection for five years. Science Education International, 29(1), 110-116

Onyekuru, B.U., \& Ibegbunam, J.O. (2013). Teaching effectiveness of secondary school teachers in Emohia Local Government Area of Rivers State, Nigeria. European Scientific Journal, 9 (28), 212-226.

Oviawe, J.I. (2016). Teacher effectiveness as correlation of students' academic achievement in Basic Technology in Nigeria. International Journal of Academic Research in Progressive Education and Development, 5(2), 111-119.

Sagar, P. \& Parveen, S.S. (2017). A study of teaching effectiveness among secondary school teachers. Scholarly Research Journal for Interdisciplinary Studies, 4(36). https://doi.org/10.21922/srjis.v4i36.10027. 
Saikia, P. (2016). Teacher effectiveness of the secondary school teachers of Bokakhart sub-division, North East India. Retrieved September 1,

2019 from https://www.academia.edu/32630712/Teacher_effectiveness_of_the_secondary_school_teachers_of_Bokakhat_sub-division

Saini, M.K., \& Joshi, A. (2015). Teacher effectiveness in relations to personality types of secondary school teachers. Remarking, $1(3), 49-51$.

Salau, A. (2018). Nigeria and quest for comprehensive literacy: The STEM solution. Retrieved September 1, 2019 from https://opinion.premiumtimesng.com/2018/12/07/nigeria-an...Comprehensive-literacy-the-stem-solution-by-adetolasalau/

Shah, S.R. \& Udgaonkar, U. S. (2018). Influence of gender and age of teachers on teaching: Students' perspective. International Journal of Current Microbiology and Applied Sciences, 7(1), 2436-2441.

Tickly, L., Joubert, M., Barret, A. M., Bainton, D., Cameron, L. \& Doyle, H. (2018). Supporting secondary school STEM education for sustainable development in Africa. Retrieved September 1, 2019 from http://www.bristol.ac.uk/medialibrary/sites/education/documents/Supporting\%20Secondary\%20School\%20STEM\%20Education\%20for\%20Sustainabale \%20Development\%20in\%20Africa.pdf

Ugo, E.A., \& Akpoghol, T.V. (2016). Improving Science, Technology, Engineering and Mathematics (STEM) program in secondary schools in Benue State, Nigeria: Challenges and Prospects. Asia Pacific Journal of Education, Arts and Science, 3(2), 6-15.

Yusuf, K. (2018). Lack of STEM education is holding back growth and opportunities in Africa. Retrieved September 1, 2019 from https://www.accaglobal.com/in/en/member/member/accounting-business/2018/06/insights/stem-education.html 